\title{
The Association and Interaction of Aldehyde Dehydrogenase 2 Polymorphisms with Food Group Intake and Probability of Having Non-Alcoholic Fatty Liver Disease
}

This article was published in the following Dove Press journal:

Diabetes, Metabolic Syndrome and Obesity: Targets and Therapy

\section{Xiaoyan Hao}

Qiang Zeng

Health Management Institute, The Second Medical Center \& National Clinical Research Center for Geriatric Diseases, Chinese PLA General Hospital, Beijing, People's Republic of China
Correspondence: Qiang Zeng Health Management Institute, The Second Medical Center \& National Clinical Research Center for Geriatric Diseases, Chinese PLA General Hospital, Beijing, People's Republic of China

Tel +86-|0-6829575|

Fax +86-2I-64085875

Email hmi2020@I26.com
Purpose: This study investigated the association between the aldehyde dehydrogenase 2 (ALDH2) rs671 polymorphism, food group intake, and the probability of having nonalcoholic fatty liver disease (NAFLD) in a Chinese population.

Patients and Methods: A total of 3506 adults were enrolled in this study, and all underwent physical examinations and genotyping of polymorphisms with polymerase chain reaction. Participants filled out a dietary questionnaire that was used to assess the frequency and quantity of food consumption.

Results: We found that milk groups were associated with a lower probability of developing NAFLD. On the contrary, meat and salted and smoked foods were associated with a higher probability of NAFLD. However, the influences of salted and smoked foods and fresh fruit and vegetables on NAFLD were obviously different in the two genotype groups. Salted and smoked foods intake was a factor associated with a higher probability of having NAFLD or nonalcoholic steatohepatitis (NASH) in the A genotype group, but there was no effect in the $\mathrm{G}$ genotype group. Moreover, eating salted and smoked foods several times per week was associated with a higher probability of having NAFLD than seldom consuming them. Consumption of fresh fruit and vegetables was not a factor influencing the probability of having NAFLD in the A genotype group, and there was no effect in the G genotype group. Further analysis of the interaction indicated that the GA +AA genotype showed an interaction with fresh fruit and vegetables and salted and smoked foods. Moreover, it was not obvious that meat intake increased the probability of having NAFLD or NASH among different genotypes.

Conclusion: Our results indicate that $A L D H 2$ rs671 GA and AA genotypes are factors associated with increased probability of NAFLD among Chinese subjects. This could stimulate the development of novel approaches for preventing NAFLD.

Keywords: rs671, NASH, genotype, foods

\section{Introduction}

The prevalence rates of non-alcoholic fatty liver disease (NAFLD) and non-alcoholic steatohepatitis (NASH) are increasing worldwide, ${ }^{1,2}$ and both conditions can lead to cirrhosis and hepatocellular carcinoma. It is crucial that patients with NAFLD undergo assessment for their risk of advanced fibrosis. ${ }^{3}$ NAFLD is reaching epidemic proportions in China, and the prevalence is $45.4 \%$ in south China. ${ }^{4}$ Therefore, it is important 
to identify modifiable risk factors of NAFLD in Chinese individuals. NAFLD is a multiple factor disease influenced by genetics, food intake, and lifestyle habits. ${ }^{5-7}$ Several studies have investigated the association between gene polymorphisms and NAFLD. ${ }^{8-11}$ Acetaldehyde dehydrogenase 2 $(\mathrm{ALDH} 2)$ is an enzyme involved in redox homeostasis and hepatic ethanol metabolism. ${ }^{12,13}$ The rs671 polymorphism (also named Glu504Lys) has been the most commonly studied. ${ }^{14}$ This G-to-L missense mutation in which the glutamate at position 504 is replaced by lysine has three genotypes: GG, GA and AA (also indicated as *1/*1, *1/*2, and *2/*2). ${ }^{15}$ The $r s 671$ polymorphism is found in $30 \%$ to $50 \%$ of East Asian populations. ${ }^{16} A L D H$ is associated with lipid peroxidation, ${ }^{17}$ which may be one of the pathological mechanisms underlying NAFLD and NASH. It could play an active role in liver dysfunction and the development of NAFLD. ${ }^{18,19}$ Previous study also reported that $A L D H 2$ is associated with higher risk for NAFLD. ${ }^{20}$ It is known that $A L D H 2$ polymorphisms can result in reduced enzyme activity. ${ }^{21}$ ALDH activities are also decreased in the progression of NASH. ${ }^{22}$ Although there is accumulating evidence indicating a relationship between $A L D H 2$ polymorphisms and NAFLD pathogenesis, ${ }^{20,23}$ there are few studies of the relationship between diet and NAFLD in subjects with different $A L D H 2$ genotypes. We conducted this investigation to clarify the associations between the ALDH2 rs671 polymorphisms, food group intake and probability of having NAFLD in Chinese subjects.

\section{Patients and Methods Subjects}

The data were collected from July 2018 to July 2019 at the Health Management Institute of Chinese PLA General Hospital. The study was conducted in accordance with the Declaration of Helsinki. All methods were performed in accordance with relevant guidelines and regulations, and all participants provided written informed consent prior to the study. The protocols involving human participants were reviewed and approved by the Institutional Ethics Committee of Chinese PLA General Hospital. All subjects underwent ultrasonography with the same equipment by the same experienced radiologist. NAFLD was diagnosed according to relevant guidelines and regulations. ${ }^{24}$ Patients were excluded if they had the following conditions: viral hepatitis; drug-induced hepatitis; hepatocellular carcinoma; excessive alcohol consumption $(\geq 30 \mathrm{~g} / \mathrm{d}$ in men or $\geq 20 \mathrm{~g} / \mathrm{d}$ in women); primary biliary cirrhosis; or severe liver, kidney, and thyroid dysfunction. Normal control individuals were selected based on abdominal ultrasonography, but those with liver disease were excluded. Hepatic fibrosis is the major cause of morbidity and mortality in patients with NASH, and the BARD Score was developed to identify patients that are at high risk of developing advanced fibrosis. $^{25}$ The BARD score was calculated for predicting NASH according to body mass index (BMI) $\geq 28=1$ point, aspartate transaminase/alanine aminotransferase ratio $\geq 0.8=$ 2 points, and diabetes $=1$ point. According to this score, we further differentiated patients with liver fibrosis from NAFLD patients. Subjects with a BARD score $>2$ points are considered to have liver fibrosis.

\section{Detection of the ALDH2 Genotype}

$A L D H 2$ polymorphisms were detected by using a gene chip hybrid analysis. DNA was extracted from the whole blood of the participants using the QIAampR DNA Mini Kit (CAT No. 51304, Germany). The $A L D H 2$ genotype was determined by a PCR-Genotyping microarray analysis of three gene types ( $A L D H 2$ Genotyping kit, BaiO, Shanghai, China).

\section{Assessment of Diet}

According to the China Health and Nutrition Survey ${ }^{26}$ and our slightly changed form ${ }^{27}$ based on the current Chinese lifestyle, all subjects were asked to provide food-related information through a self-questionnaire to enable us to assess their food intake at their first visit. The questionnaire included items on sociodemographic characteristics, smoking, eating habits, drinking, family history, and past medical history. The food groups included cereals, milk, meat, fruits, vegetables, bean products, salted and smoked foods, and fried foods. The food frequencies were ranked from 1 to 3 (1: less than 1 day per week; 2: 1-4 days/week; 3: 5-7 days/ week). The daily quantity of foods consumed was estimated as follows: cereal (100-500 g/day), meat (100-200g/day), fruits and vegetables (200 -500 g/day), sugar (30-50 g/day),

Table I Hardy-Weinberg Equilibrium in Different Genotype Groups

\begin{tabular}{|c|c|c|c|c|c|c|c|}
\hline & \multicolumn{3}{|c|}{ Genotype } & \multicolumn{2}{|c|}{$\begin{array}{l}\text { Allelic } \\
\text { Frequency }\end{array}$} & \multicolumn{2}{|c|}{ HWE } \\
\hline & GG & GA & AA & G\% & $\mathbf{A} \%$ & $\mathbf{x}^{2}$ & $\mathbf{P}$ \\
\hline NAFLD $(2175)$ & 1484 & 640 & 51 & 82.94 & 17.05 & 4.88 & 0.09 \\
\hline Control (1331) & 855 & 426 & 50 & 80.24 & 19.75 & 0.21 & 0.90 \\
\hline Total (3506) & 2339 & 1066 & 101 & 81.92 & 18.08 & 0.37 & 0.83 \\
\hline
\end{tabular}

Note: $\mathrm{P}>0.05$ indicates that the studied population was in Hardy-Weinberg equilibrium. 
Table 2 Demographic Clinical Characteristics Between NAFLD and the Control Group

\begin{tabular}{|c|c|c|c|c|c|}
\hline Characteristics & NAFLD (2|75) & Control (1331) & P-value & OR $(95 \% \mathrm{CI})$ & P-value \\
\hline Age & $54.08 \pm 7.53$ & $51.69 \pm 8.61$ & $<0.001$ & $1.04(1.03-1.05)$ & $<0.001$ \\
\hline Sex (male) & I739(79.96) & $580(46.44)$ & $<0.001$ & $4.16(3.5 I-4.93)$ & $<0.001$ \\
\hline BMI & $26.88 \pm 2.91$ & $22.82 \pm 2.43$ & $<0.001$ & $1.88(1.80-1.96)$ & $<0.001$ \\
\hline Waistline & $93.21 \pm 8.85$ & $81.32 \pm 23.56$ & $<0.001$ & $1.16(1.14-1.17)$ & $<0.001$ \\
\hline Smoking & $78 I(35.91)$ & $24 I(I 8.1 I)$ & $<0.001$ & $1.27(1.05-1.54)$ & 0.012 \\
\hline Hypertension & $507(23.31)$ & $108(8.11)$ & $<0.001$ & $2.91(2.29-3.68)$ & $<0.001$ \\
\hline Hyperlipidemia & $1585(72.87)$ & $695(52.21)$ & $<0.001$ & $1.87(1.60-2.19)$ & $<0.001$ \\
\hline Diabetes & $191(8.78)$ & $27(2.02)$ & $<0.001$ & $3.16(2.05-4.88)$ & $<0.001$ \\
\hline ALDH2(L allele carriers) & $691(31.77 \%)$ & $476(35.76 \%)$ & 0.015 & $1.19(1.04-1.38)$ & 0.014 \\
\hline
\end{tabular}

Abbreviations: $\mathrm{BMI}$, body mass index; $\mathrm{Cl}$, confidence interval; $\mathrm{OR}$, odds ratio.

and salt (6-8 g/day). The dietary intake collection method used has been formally validated in the Chinese population, ${ }^{27}$ and the other estimated diet record method is widely accepted and reliable. ${ }^{28}$

\section{Statistical Analysis}

Student's t-tests, one way analyses of variance, chi-square tests, Fisher exact tests, and binary logistic regression were performed using SPSS version 24.0 (IBM Corp., Armonk, NY, USA). Odds ratios (ORs) and 95\% confidence intervals (CIs) were calculated, and $\mathrm{P}<0.05$ was considered statistically significant.

\section{Results}

\section{Hardy-Weinberg Equilibrium}

The results showed that the genotypes conformed to Hardy-Weinberg equilibrium. Each sample was assigned a genotype, and the frequency of each genotype and allele was calculated in the NAFLD and control groups. The respective allelic frequencies of $\mathrm{G}$ and $\mathrm{A}$ were $82.94 \%$ and $17.05 \%$ in the NAFLD group $\left(\mathrm{X}^{2}=4.88, \mathrm{P}>0.05\right)$, $80.24 \%$ and $19.75 \%$ in the control group $\left(X^{2}=0.21, P>\right.$ 0.05 ), and $81.92 \%$ and $18.08 \%$ in the general population $\left(\mathrm{X}^{2}=0.37, \mathrm{P}>0.05\right)($ Table 1$)$.

\section{Clinical Characteristics}

A total of 3506 individuals (79.96\% male, $20.04 \%$ female) participated in this study, including 2175 NAFLD patients $(\mathrm{GG}=1484, \mathrm{GA}=640$, and $\mathrm{AA}=51)$ and 1331 controls $(\mathrm{GG}=855, \mathrm{GA}=426$, and $\mathrm{AA}=50)$. The average ages for NAFLD patients and controls were $54.08 \pm 7.53$ and $51.69 \pm 8.61$ years, respectively. There were significant differences in age, sex, BMI, waistline circumference,
Table 3 ALDH2 Polymorphisms and Food Groups in Relation to the Risk of NAFLD

\begin{tabular}{|c|c|c|}
\hline Food Groups (Frequencies) & OR $(95 \% \mathrm{CI})$ & P-value \\
\hline Milk & & $<0.001$ \\
\hline I & I (ref) & \\
\hline 2 & $0.69(0.59-0.83)$ & $<0.001$ \\
\hline 3 & $0.65(0.53-0.80)$ & $<0.001$ \\
\hline Bean products & & 0.911 \\
\hline 1 & I (ref) & \\
\hline 2 & & 0.742 \\
\hline 3 & & 0.939 \\
\hline Fresh fruit and vegetables & & $<0.001$ \\
\hline I & I (ref) & \\
\hline 2 & $0.59(0.31-1.10)$ & 0.099 \\
\hline 3 & $0.38(0.20-0.70)$ & 0.002 \\
\hline Salted and smoked foods & & 0.002 \\
\hline I & I (ref) & \\
\hline 2 & $1.19(1.02-1.40)$ & 0.028 \\
\hline 3 & $1.62(1.21-2.17)$ & 0.001 \\
\hline Meat & & $<0.001$ \\
\hline I & $\mathrm{I}(\mathrm{ref})$ & \\
\hline 2 & $1.78(\mid .26-2.5 \mathrm{I})$ & 0.001 \\
\hline 3 & $2.37(1.68-3.34)$ & $<0.001$ \\
\hline Fried foods & & 0.001 \\
\hline I & I(ref) & \\
\hline 2 & $1.24(1.05-1.45)$ & 0.009 \\
\hline 3 & $1.03(0.73-1.45)$ & 0.088 \\
\hline Cereals & & 0.298 \\
\hline 1 & $\mathrm{I}(\mathrm{ref})$ & \\
\hline 2 & & 0.121 \\
\hline 3 & & 0.144 \\
\hline
\end{tabular}

Notes: I, less than I day per week; 2, I-4 days/week; 3, 5-7 days/week. These factors (bean products, cereals) were not included in the regression equation. These parameters were after adjusting for age, sex, BMI, waistline circumference, smoking, hyperlipidemia, hypertension, and diabetes.

Abbreviations: $\mathrm{BMI}$, body mass index; $\mathrm{Cl}$, confidence interval; $\mathrm{OR}$, odds ratio. 
Table 4 Comparison of the Relationship Between Food Groups and NAFLD in the G and A Genotype Groups

\begin{tabular}{|c|c|c|c|c|}
\hline \multirow{2}{*}{$\frac{\text { Food Groups }}{\text { (Frequencies) }}$} & \multicolumn{2}{|l|}{ GG Genotype } & \multicolumn{2}{|c|}{ GA + AA Genotype } \\
\hline & OR (95\% Cl) & P-value & OR $(95 \% \mathrm{CI})$ & P-value \\
\hline Milk & & 0.001 & & 0.004 \\
\hline I & $\mathrm{I}(\mathrm{ref})$ & & I (ref) & \\
\hline 2 & $0.7 \mathrm{I}(0.57-0.87)$ & 0.001 & $0.66(0.49-0.87)$ & 0.003 \\
\hline 3 & $0.65(0.5 I-0.84)$ & 0.001 & $0.61(0.43-0.87)$ & 0.006 \\
\hline Bean products & & 0.588 & & 0.460 \\
\hline I & I (ref) & & I (ref) & \\
\hline 2 & & 0.303 & & 0.668 \\
\hline 3 & & 0.438 & & 0.266 \\
\hline Fresh fruit and vegetables & & $<0.001$ & & 0.006 \\
\hline I & I (ref) & & I (ref) & \\
\hline 2 & $0.98(0.48-1.99)$ & 0.949 & $0.06(0.01-0.52)$ & 0.010 \\
\hline 3 & $0.58(0.29-1.16)$ & 0.125 & $0.05(0.0 I-0.4 I)$ & 0.005 \\
\hline Salted and smoked foods & & 0.159 & & 0.003 \\
\hline I & I (ref) & & I (ref) & \\
\hline 2 & & 0.519 & $1.4 \mathrm{I}(1.09-1.82)$ & 0.008 \\
\hline 3 & & 0.131 & $2.28(1.24-3.19)$ & 0.005 \\
\hline Meat & & $<0.001$ & & 0.006 \\
\hline I & I (ref) & & I (ref) & \\
\hline 2 & $1.65(1.11-2.46)$ & 0.013 & $2.58(1.29-5.15)$ & 0.007 \\
\hline 3 & $2.40(1.6 I-3.58)$ & $<0.001$ & $2.98(1.50-5.94)$ & 0.002 \\
\hline Fried foods & & 0.005 & & 0.208 \\
\hline I & I (ref) & & I (ref) & \\
\hline 2 & $1.56(I .0 I-2.21)$ & 0.007 & & 0.088 \\
\hline 3 & $1.21(085-1.73)$ & 0.280 & & 0.355 \\
\hline Cereals & & 0.372 & & 0.170 \\
\hline I & I (ref) & & I (ref) & \\
\hline 2 & & 0.173 & & 0.321 \\
\hline 3 & & 0.160 & & 0.552 \\
\hline
\end{tabular}

Notes: I, less than I day per week; 2, I-4 days/week; 3, 5-7 days/week. These factors (cereals and bean products in two groups; salted and smoked foods in the G genotype group; fried foods in the A genotype group) were not included in the regression equation. These parameters were after adjusting for age, sex, BMI, waistline circumference, smoking, hyperlipidemia, hypertension, and diabetes.

smoking, hypertension, hyperlipidemia, and diabetes between the NAFLD and control groups $(\mathrm{P}<0.05)$ (Table 2). The significant variables identified as risk factors of NAFLD were age, sex, BMI, waistline circumference, smoking, hyperlipidemia, hypertension, diabetes. Notably, those carrying GA or AA genotype were at a higher risk of NAFLD $(\mathrm{OR}=1.19,95 \% \mathrm{CI}$ : 1.04-1.38, $\mathrm{P}=0.014)$.

\section{Food Groups and Baseline NAFLD}

\section{Characteristics}

According to the results shown in Table 3, consuming milk groups were associated with a lower probability of developing NAFLD. Conversely, meat and salted and smoked food intake were associated with a higher probability of NAFLD. There were no statistically significant differences for cereals, fresh fruit and vegetables, fried foods, or bean products. (Table 3).

\section{Comparison of the Effects of Food Groups Between Genotype Groups}

The influence of most food groups, such as, cereals, milk, fried foods, meat, and bean products was not noticeably different between the two genotypes. However, there were differences in salted and smoked foods and fresh fruit and vegetables. The intake of salted and smoked foods was 
a factor associated with a higher probability of having NAFLD in the A genotype group, but there was no effect in the $G$ genotype group. Moreover, eating salted and smoked foods several times a week was associated with a higher probability of NAFLD than seldom intake. Consumption of fresh fruit and vegetables was not a factor influencing the probability of having NAFLD in the A genotype group, and there was no effect in the G genotype group (Table 4).

\section{The Food Groups and Base Characteristics of NASH}

According to the BARD score, there were $1484 \mathrm{NASH}$ patients in the GG group and 691 in the GA and AA groups. Table 5 shows that meat group intake was associated with a higher probability of having NASH. However, no significance was found for cereals, bean products, fresh fruit and vegetables, milk, salted and smoked foods, or fried foods (Table 5).

\section{Comparison of the Effects of the Salted and Smoked Food and Meat on Liver Fibrosis Between Genotype Groups}

Table 6 shows that the influences of salted and smoked foods and meat on liver fibrosis were obviously different in the two groups. Salted and smoked food intake was associated with a higher probability of developing NASH in the A genotype group but not the $\mathrm{G}$ genotype group. Conversely, meat intake was associated with a higher probability of developing NASH in the G genotype group but not the A genotype group. No significant association was found in either group for cereals, bean products, milk, fried foods, or fresh fruit and vegetables (Table 6).

\section{Interaction of Genotypes with Food Groups for NAFLD}

The interaction of $r s 671$ polymorphisms with food groups for NAFLD is shown in Table 7.

The results were calculated using logistic regression analysis adjusting for age, sex, BMI, waistline circumference, smoking, hyperlipidemia, hypertension, and diabetes. With food frequencies 1 as a reference, the GA +AA genotype showed an interaction with fresh fruit and vegetables (2: $\mathrm{OR}=0.56, \mathrm{P}<0.001 ; 3: \mathrm{OR}=0.69, \mathrm{P}=0.001)$ Moreover, the GA+AA genotype showed an interaction with salted and smoked foods $(2$ : $\mathrm{OR}=1.31, \mathrm{P}=0.039 ; 3$ :
Table 5 ALDH2 Polymorphisms and Food Groups in Relation to the Risk of NASH

\begin{tabular}{|c|c|c|}
\hline Food Groups(Frequencies) & OR $(95 \% \mathrm{CI})$ & P-value \\
\hline Milk & & 0.979 \\
\hline 1 & I (ref) & \\
\hline 2 & & 0.924 \\
\hline 3 & & 0.836 \\
\hline Bean products & & 0.970 \\
\hline 1 & I(ref) & \\
\hline 2 & & 0.880 \\
\hline 3 & & 0.991 \\
\hline Fresh fruit and vegetables & & 0.781 \\
\hline 1 & $\mathrm{I}($ ref) & \\
\hline 2 & & 0.889 \\
\hline 3 & & 0.925 \\
\hline Salted and smoked foods & & 0.074 \\
\hline 1 & I (ref) & \\
\hline 2 & & 0.258 \\
\hline 3 & & 0.126 \\
\hline Meat & & 0.002 \\
\hline I & I (ref) & \\
\hline 2 & $2.00(1.12-3.57)$ & 0.018 \\
\hline 3 & $2.74(1.53-4.93)$ & 0.001 \\
\hline Fried foods & & 0.332 \\
\hline 1 & I (ref) & \\
\hline 2 & & 0.152 \\
\hline 3 & & 0.463 \\
\hline Cereals & & 0.399 \\
\hline $\mathrm{I}$ & $\mathrm{I}(\mathrm{ref})$ & \\
\hline 2 & & 0.626 \\
\hline 3 & & 0.495 \\
\hline
\end{tabular}

Notes: I, less than I day per week; 2, I-4 days/week; 3, 5-7 days/week. Data were obtained from the logistic regression analysis based on Chinese people with complete covariable data who were in the NAFLD group at the Health Management Institute $(n=2175)$. These factors (cereals, bean products, fresh fruit and vegetables, milk, salted and smoked foods, fried foods) were not included in the regression equation. These parameters were after adjusting for age, sex, BMI, waistline circumference, smoking, hyperlipidemia, hypertension, and diabetes.

$\mathrm{OR}=2.11, \mathrm{P}=0.002$ ). There were no other food groups that had interactions with the GG genotype or GA+AA genotype with regard to the probability of having NAFLD (Table 7).

\section{Discussion}

\section{Related Factors of NAFLD and ALDH2 Genotypes}

Our results indicate that there is a relationship between food intake and NAFLD in different $A L D H 2$ genotype groups. First, NAFLD occurrence was significantly higher in 
Table 6 Comparison of the Relationship Between Food Groups and Liver Fibrosis in the G and A Genotype Groups

\begin{tabular}{|c|c|c|c|c|}
\hline \multirow{2}{*}{$\begin{array}{l}\text { food Groups } \\
\text { (Frequencies) }\end{array}$} & \multicolumn{2}{|l|}{ GG Genotype } & \multicolumn{2}{|c|}{ GA + AA Genotype } \\
\hline & OR (95\% Cl) & P-value & OR $(95 \% \mathrm{Cl})$ & P-value \\
\hline Milk & & 0.596 & & 0.275 \\
\hline I & I (ref) & & I (ref) & \\
\hline 2 & & 0.350 & & 0.137 \\
\hline 3 & & 0.425 & & 0.237 \\
\hline Bean products & & 0.869 & & 0.830 \\
\hline I & $\mathrm{I}(\mathrm{ref})$ & & I (ref) & \\
\hline 2 & & 0.815 & & 0.778 \\
\hline 3 & & 0.909 & & 0.842 \\
\hline Fresh fruit and vegetables & & 0.944 & & 0.14 \\
\hline I & I (ref) & & I (ref) & \\
\hline 2 & & 0.982 & & 0.194 \\
\hline 3 & & 0.928 & & 0.461 \\
\hline Salted and smoked foods & & 0.970 & & 0.02 \\
\hline I & I (ref) & & I (ref) & \\
\hline 2 & & 0.808 & $1.58(0.99-2.5 \mathrm{I})$ & 0.041 \\
\hline 3 & & 0.917 & $3.37(1.17-9.67)$ & 0.021 \\
\hline Meat & & 0.010 & & 0.161 \\
\hline I & $I(r e f)$ & & I (ref) & \\
\hline 2 & $2.58(1.29-5.16)$ & 0.007 & & 0.056 \\
\hline 3 & $2.96(1.46-5.97)$ & 0.002 & & 0.073 \\
\hline Fried foods & & 0.596 & & 0.108 \\
\hline I & I(ref) & & I (ref) & \\
\hline 2 & & 0.607 & & 0.035 \\
\hline 3 & & 0.462 & & 0.575 \\
\hline Cereals & & 0.683 & & 0.369 \\
\hline I & I (ref) & & I (ref) & \\
\hline 2 & & 0.593 & & 0.371 \\
\hline 3 & & 0.791 & & 0.576 \\
\hline
\end{tabular}

Notes: I, less than I day per week; 2, I-4 days/week; 3, 5-7 days/week. These factors (cereals, fried foods, fresh fruit and vegetables, milk, bean products in two groups; salted and smoked foods in the G genotype group; meat in the A genotype group) were not included in the regression equation. These parameters were after adjusting for age, sex, BMI, waistline circumference, smoking, hyperlipidemia, hypertension, and diabetes.

participants who with the $A L D H 2$ A genotype than those with the $\mathrm{G}$ genotype. The AA allele of the $A L D H 2$ polymorphism is associated with susceptibility to NAFLD, ${ }^{20}$ and it was significantly associated with NAFLD in a Japanese population. Another study showed that the patatin-like phospholipase domain-containing protein 3 (PNPLA3) I148M polymorphism was the main genetic risk factor for metabolic liver disease ranging from hepatic steatosis to liver inflammation, fibrosis, cirrhosis, and hepatocellular carcinoma. ${ }^{29}$ Nutritional control of PNPLA3 is reportedly affected by transcriptional up-regulation, ${ }^{30}$ which further supports the association between gene polymorphisms and NAFLD. Second, we demonstrated that factors related to NAFLD were age, sex, BMI, waistline circumference, smoking, hyperlipidemia, hypertension, and diabetes, which are consistent with previous findings. ${ }^{31}$ A review showed that individuals with NAFLD had a high frequency of metabolic comorbidities, and this study reported that it would probably emerge as the leading cause of end-stage liver disease in the coming decades. ${ }^{31}$ It is therefore important to prevent and control the related factors of NAFLD.

\section{Influence of Food Groups on ALDH2 Genotypes}

We found that milk groups were associated with a lower probability of developing NAFLD. Conversely, meat and salted and 
Table 7 The Association and Interaction of Genotypes with Food Groups for NAFLD

\begin{tabular}{|c|c|c|c|c|}
\hline \multirow{2}{*}{$\begin{array}{l}\text { food Groups } \\
\text { (Frequencies) }\end{array}$} & \multicolumn{2}{|c|}{ GG Genotype × Food Groups } & \multicolumn{2}{|c|}{ GA +AA Genotype $\times$ Food Groups } \\
\hline & OR $(95 \% \mathrm{Cl})$ & P-value & OR $(95 \% \mathrm{CI})$ & P-value \\
\hline Milk & & 0.496 & & 0.940 \\
\hline 1 & & & $\mathrm{I}(\mathrm{ref})$ & \\
\hline 2 & & 0.483 & & 0.807 \\
\hline 3 & & 0.469 & & 0.920 \\
\hline Bean products & & 0.628 & & 0.392 \\
\hline I & I (ref) & & $\mathrm{I}(\mathrm{ref})$ & \\
\hline 2 & & 0.462 & & 0.762 \\
\hline 3 & & 0.866 & & 0.258 \\
\hline Fresh fruit and vegetables & & 0.053 & & $<0.001$ \\
\hline 1 & & & I (ref) & \\
\hline 2 & & 0.016 & $0.57(0.42-0.77)$ & $<0.001$ \\
\hline 3 & & 0.018 & $0.7 I(0.57-0.88)$ & 0.002 \\
\hline Salted and smoked foods & & 0.529 & & 0.008 \\
\hline I & I (ref) & & I (ref) & \\
\hline 2 & & 0.545 & $1.17(1.01-1.37)$ & 0.039 \\
\hline 3 & & 0.275 & $1.49(1.13-1.97)$ & 0.005 \\
\hline Meat & & 0.247 & & 0.123 \\
\hline 1 & & & $I($ ref) & \\
\hline 2 & & 0.786 & & 0.183 \\
\hline 3 & & 0.646 & & 0.509 \\
\hline Fried foods & & 0.018 & & 0.848 \\
\hline 1 & & & $I($ ref) & \\
\hline 2 & & 0.006 & & 0.752 \\
\hline 3 & & 0.917 & & 0.586 \\
\hline Cereals & & 0.138 & & 0.155 \\
\hline 1 & $\mathrm{I}(\mathrm{ref})$ & & $I($ ref) & \\
\hline 2 & & 0.061 & & 0.221 \\
\hline 3 & & 0.103 & & 0.401 \\
\hline
\end{tabular}

Notes: I, less than I day per week; 2, I-4 days/week; 3, 5-7 days/week. These factors (cereals, fried foods, meat, milk, bean products in two groups; fresh fruit and vegetables and salted and smoked foods in the G genotype group) were not included in the regression equation. These parameters were after adjusting for age, sex, BMI, waistline circumference, smoking, hyperlipidemia, hypertension, and diabetes.

smoked foods intake were associated with a higher probability of having NAFLD. According to our logistic regression results, the influences of cereals, milk, fried foods, meat, and bean products on NAFLD were not significantly different in the $\mathrm{G}$ and A genotype groups. However, obvious differences were observed for salted and smoked foods and fresh fruit and vegetables. It is well known that the gene-diet interaction plays an important role in human diseases. For example, the findings of a recent genetic study revealed that the lactase polymorphisms in combination with higher dairy intake could increase the risk for metabolic syndrome. ${ }^{32}$ Researchers investigating the relationships between milk intake, lactase polymorphisms, and bone health found that the lactase polymorphisms influenced bone mineral density and bone fractures in an Austrian population. ${ }^{33}$ Our study showed that A genotype in combination with high salted and smoked food intake could increase the probability of having NAFLD. However, the A genotype in combination with fresh fruit and vegetable intake could decrease the probability of having NAFLD. This significant difference remained after adjusting for age, sex, BMI, waistline circumference, smoking, hyperlipidemia, hypertension, and diabetes. We speculate that it may be related to lipid peroxidation in the food. Lipid peroxidation is known to play a vital role in the pathogenesis and severity of NAFLD and NASH. ${ }^{18,34}$ Importantly, lipid peroxidation was associated with the ALDH2 rs671 
polymorphism. ${ }^{17,35}$ ALDH2 rs671 is described as a missense variant that leads to decreased ALDH2 enzyme activity. ${ }^{36}$ One study showed that ALDH2 is an anti-lipid peroxidation factor. ${ }^{37}$ Theoretically, the decrease in ALDH2 enzyme activity leads to more lipid peroxidation products. We therefore speculate that anti-lipid peroxidation is decreased in subjects with the A genotype group of $A L D H 2$. In addition, fresh fruits and vegetables are anti-lipid peroxidation foods. ${ }^{38}$ We found that consuming them was a protective factor against NAFLD in the A genotype group but not the $\mathrm{G}$ genotype group. Therefore, subjects with the A genotype could consume more fresh fruit and vegetables to prevent NAFLD. Furthermore, salted and smoked foods might promote lipid peroxidation. Smoked, comminuted pork or poultry contain high levels of lipid peroxidation products. ${ }^{39}$ Detection of malondialdehyde, product of the lipid peroxidation process, was significantly higher in frankfurters than raw meat, ${ }^{40}$ which further supports our results. In our study, salted and smoked foods intake is a factor associated with a higher probability of having NAFLD or NASH in the A genotype group but not the G genotype group. Furthermore, we found that consuming meat was associated with a higher probability of having NASH in the $\mathrm{G}$ genotype group but not the A genotype group. However, we did not find a significant interaction between meat intake and the G genotype or A genotypes. Moreover, it was not obvious that meat intake increased the probability of having NAFLD or NASH among different genotypes. Collectively, the results indicate that dietary intervention may be more effective for decreasing the prevalence of NAFLD in subjects with specific genotypes.

\section{Limitations}

Our results should be considered in the context of several limitations. First, we combined the $A L D H 2 \mathrm{GA}$ and AA genotypes into one group. Because the $A L D H 2$ AA genotype sample size was small, the statistical power was low. We recognized that we should include the A genotype as a group so it could affect ALDH2 enzyme activity. Second, we only studied a limited range of consumption quantities of each food, and additional work is needed to obtain more detailed diet and energy intake information. Third, we only speculated that lipid peroxidation plays a role, and we will further study this effect in the future.

\section{Conclusions}

Our results demonstrate that $A L D H 2$ rs671 GA and AA genotypes are risk factors for NAFLD among Chinese subjects. The interaction between food intake and $A L D H 2$ may affect NAFLD incidence in the Chinese population.

\section{Acknowledgments}

We thank all study participants for their cooperation.

\section{Funding}

This study was supported by the National Natural Science Foundation of China (81872920).

\section{Disclosure}

The authors declare no conflicts of interest.

\section{References}

1. Stefan N, Haring H-U, Cusi K. Non-alcoholic fatty liver disease: causes, diagnosis, cardiometabolic consequences, and treatment strategies. Lancet Diabetes Endocrinol. 2019;7(4):313-324. doi:10.1016/S2213-8587(18)30154-2

2. Estes C, Anstee QM, Arias-Loste MT, et al. Modeling NAFLD disease burden in China, France, Germany, Italy, Japan, Spain, United Kingdom, and United States for the period 2016-2030. J Hepatol. 2018;69(4):896-904. doi:10.1016/j.jhep.2018.05.036

3. Tapper EB, Loomba R. Noninvasive imaging biomarker assessment of liver fibrosis by elastography in NAFLD. Nature Reviews Gastroenterology \& Hepatology. 2018;15(5):274-282. doi:10.1038/ nrgastro.2018.10

4. Yi M, Chen R-P, Yang R, Chen H. Increased prevalence and risk of non-alcoholic fatty liver disease in overweight and obese patients with Type 2 diabetes in South China. Diabet Med. 2017;34 (4):505-513. doi:10.1111/dme.13174

5. Zhang S, Gu Y, Lu M, et al. Association between edible mushroom intake and the prevalence of newly diagnosed non-alcoholic fatty liver disease: results from the TCLSIH Cohort Study in China. $\mathrm{Br}$ J Nutr. 2019;1-26.

6. Romero-Gomez M, Zelber-Sagi S, Trenell M. Treatment of NAFLD with diet, physical activity and exercise. J Hepatol. 2017;67 (4):829-846. doi:10.1016/j.jhep.2017.05.016

7. Kalafati IP, Dimitriou M, Borsa D, et al. Fish intake interacts with TM6SF2 gene variant to affect NAFLD risk: results of a case-control study. Eur J Nutr. 2019;58(4):1463-1473.

8. Kong L, Lu Y, Zhang S, Nan Y, Qiao L. Role of nutrition, gene polymorphism, and gut microbiota in non-alcoholic fatty liver disease. Discov Med. 2017;24(131):95-106.

9. Y ZZ X, Liu S, Xiao Y, Miao M, Dong Q, Xin Y. Association of Nonalcoholic Fatty Liver Disease and Coronary Artery Disease with FADS2 rs3834458 Gene Polymorphism in the Chinese Han Population. Gastroenterol Res Pract. 2019.

10. Liu M, Liu S, Shang M, et al. Association between ADIPOQ G276T and $\mathrm{C} 11377 \mathrm{G}$ polymorphisms and the risk of non-alcoholic fatty liver disease: an updated meta-analysis. Molecular Genetics \& Genomic Medicine. 2019;7(5):e624. doi:10.1002/mgg3.624

11. Sliz E, Sebert S, Wurtz P, et al. NAFLD risk alleles in PNPLA3, TM6SF2, GCKR and LYPLAL1 show divergent metabolic effects. Hum Mol Genet. 2018;27(12):2214-2223. doi:10.1093/hmg/ddy124

12. Wakabayashi Y, Tamura Y, Kouzaki K, et al. Acetaldehyde dehydrogenase 2 deficiency increases mitochondrial reactive oxygen species emission and induces mitochondrial protease $\mathrm{Omi} / \mathrm{HtrA} 2$ in skeletal muscle. American Journal of Physiology-Regulatory, Integrative and Comparative Physiology. 2020;318(4):R677-R690. doi:10.1152/ ajpregu.00089.2019 
13. Yao C-T, Lai C-L, Yin S-J. Steady-state metabolism of ethanol in perfused rat livers treated with cyanamide: quantitative analysis of acetaldehyde effects on the metabolic flux rates. Alcoholism: Clinical and Experimental Research. 2015;39(5):798-807. doi:10.1111/ acer. 12701

14. Ma C, Yu B, Zhang W, Wang W, Zhang L, Zeng Q. Associations between aldehyde dehydrogenase 2 (ALDH2) rs671 genetic polymorphisms, lifestyles and hypertension risk in Chinese Han people. Sci Rep. 2017;7(1):11136. doi:10.1038/s41598-017-11071-w

15. Huang P-H, Hu -C-C, Chien C-H, et al. The Defective Allele of Aldehyde Dehydrogenase 2 Gene is Associated with Favorable Postoperative Prognosis in Hepatocellular Carcinoma. J Cancer. 2019;10(23):5735-5743. doi:10.7150/jca.33221

16. Chen C-H, Budas GR, Churchill EN, Disatnik M-H, Hurley TD, Mochly-Rosen D. Activation of aldehyde dehydrogenase-2 reduces ischemic damage to the heart. Science. 2008;321(5895):1493-1495. doi:10.1126/science.1158554

17. Vasiliou V, Pappa A, Estey T. Role of human aldehyde dehydrogenases in endobiotic and xenobiotic metabolism. Drug Metab Rev. 2004;36(2):279-299. doi:10.1081/DMR-120034001

18. Bellanti F, Villani R, Facciorusso A, Vendemiale G, Serviddio G. Lipid oxidation products in the pathogenesis of non-alcoholic steatohepatitis. Free Radic Biol Med. 2017;111:173-185. doi:10.1016/j.freeradbiomed.2017.01.023

19. Koliaki C, Szendroedi J, Kaul K, et al. Adaptation of hepatic mitochondrial function in humans with non-alcoholic fatty liver is lost in steatohepatitis. Cell Metab. 2015;21(5):739-746. doi:10.1016/j. cmet.2015.04.004

20. Oniki K, Morita K, Watanabe T, et al. The longitudinal effect of the aldehyde dehydrogenase $2 * 2$ allele on the risk for nonalcoholic fatty liver disease. Nutr Diabetes. 2016;6(5):e210. doi:10.1038/ nutd.2016.17

21. Lin C-Y, Yu R-L, Wu R-M, Tan C-H. Effect of ALDH2 on Sleep Disturbances in Patients with Parkinson's Disease. Sci Rep. 2019;9 (1):18950. doi:10.1038/s41598-019-55427-w

22. Li H, Toth E, Cherrington NJ. Alcohol Metabolism in the Progression of Human Nonalcoholic Steatohepatitis. Toxicol Sci. 2018;164 (2):428-438. doi:10.1093/toxsci/kfy106

23. Stachowicz A, Olszanecki R, Suski M, et al. Mitochondrial aldehyde dehydrogenase activation by Alda-1 inhibits atherosclerosis and attenuates hepatic steatosis in apolipoprotein E-knockout mice. $J \mathrm{Am}$ Heart Assoc. 2014;3(6):e001329. doi:10.1161/JAHA.114.001329

24. Fan JG, Wei L, Zhuang H. National Workshop on Fatty L, Alcoholic Liver Disease CSoHCMA, Fatty Liver Disease Expert Committee CMDA. Guidelines of prevention and treatment of nonalcoholic fatty liver disease (2018, China). J Dig Dis. 2019;20(4):163-173. doi:10.1111/1751-2980.12685

25. Harrison SA, Oliver D, Arnold HL, Gogia S, Neuschwander-Tetri BA. Development and validation of a simple NAFLD clinical scoring system for identifying patients without advanced disease. Gut. 2008;57(10):1441-1447. doi:10.1136/gut.2007.146019

26. Ge K. Dietary pattern and physical development in China- based on the 1992 national nutrition survey. Asia Pac J Clin Nutr. 1995;4 (Suppl 1):19-23.
27. Zeng Q, Li F, Xiang T, et al. Influence of food groups on plasma total homocysteine for specific MTHFR C677T genotypes in Chinese population. Mol Nutr Food Res. 2017;61(2):2. doi:10.1002/ mnfr.201600351

28. Bonifacj C, Gerber M, Scali J, Daures JP. Comparison of dietary assessment methods in a southern French population: use of weighed records, estimated-diet records and a food-frequency questionnaire. Eur J Clin Nutr. 1997;51(4):217-231. doi:10.1038/sj.ejcn.1600387

29. Liu Y-L, Patman GL, Leathart JB, et al. Carriage of the PNPLA3 rs738409 $\mathrm{C}>\mathrm{G}$ polymorphism confers an increased risk of nonalcoholic fatty liver disease associated hepatocellular carcinoma. J Hepatol. 2014;61(1):75-81. doi:10.1016/j.jhep.2014.02.030

30. Huang Y, He S, Li JZ, et al. A feed-forward loop amplifies nutritional regulation of PNPLA3. Proc Natl Acad Sci U S A. 2010;107 (17):7892-7897. doi:10.1073/pnas.1003585107

31. Younossi Z, Anstee QM, Marietti M, et al. Global burden of NAFLD and NASH: trends, predictions, risk factors and prevention. Nat Rev Gastroenterol Hepatol. 2018;15(1):11-20.

32. Almon R, Alvarez-Leon EE, Engfeldt P, Serra-Majem L, Magnuson A, Nilsson TK. Associations between lactase persistence and the metabolic syndrome in a cross-sectional study in the Canary Islands. Eur J Nutr. 2010;49(3):141-146. doi:10.1007/s00394-0090058-2

33. Obermayer-Pietsch BM, Bonelli CM, Walter DE, et al. Genetic predisposition for adult lactose intolerance and relation to diet, bone density, and bone fractures. J Bone Miner Res. 2003;19(1):42-47. doi:10.1359/jbmr.0301207

34. Ore A, Akinloye OA. Oxidative Stress and Antioxidant Biomarkers in Clinical and Experimental Models of Non-Alcoholic Fatty Liver Disease. Medicina. 2019;55(2):2. doi:10.3390/medicina55020026

35. Hoshi H, Hao W, Fujita Y, et al. Aldehyde-stress resulting from Aldh2 mutation promotes osteoporosis due to impaired osteoblastogenesis. J Bone Miner Res. 2012;27(9):2015-2023. doi:10.1002/jbmr.1634

36. Kimura M, Yokoyama A, Higuchi S. Aldehyde dehydrogenase-2 as a therapeutic target. Expert Opin Ther Targets. 2019;23(11):955-966. doi:10.1080/14728222.2019.1690454

37. Cao S, Bian Y, Zhou X, et al. A small-molecule activator of mitochondrial aldehyde dehydrogenase 2 reduces the severity of cerulein-induced acute pancreatitis. Biochem Biophys Res Commun. 2020;522(2):518-524. doi:10.1016/j.bbrc.2019.11.128

38. La Vecchia C, Tavani A. Fruit and vegetables, and human cancer. Eur j Cancer Prevent. 1998;7(1):3-8.

39. Olsen E, Vogt G, Veberg A, Ekeberg D, Nilsson A. Analysis of early lipid oxidation in smoked, comminuted pork or poultry sausages with spices. J Agric Food Chem. 2005;53(19):7448-7457. doi:10.1021/ jf050886w

40. Reitznerova A, Sulekova M, Nagy J, et al. Lipid Peroxidation Process in Meat and Meat Products: A Comparison Study of Malondialdehyde Determination between Modified 2-Thiobarbituric Acid Spectrophotometric Method and Reverse-Phase High-Performance Liquid Chromatography. Molecules. 2017;22 (11):11. doi:10.3390/molecules22111988

Diabetes, Metabolic Syndrome and Obesity: Targets and Therapy

Dovepress

\section{Publish your work in this journal}

Diabetes, Metabolic Syndrome and Obesity: Targets and Therapy is an international, peer-reviewed open-access journal committed to the rapid publication of the latest laboratory and clinical findings in the fields of diabetes, metabolic syndrome and obesity research. Original research, review, case reports, hypothesis formation, expert opinion and commentaries are all considered for publication. The manuscript management system is completely online and includes a very quick and fair peer-review system, which is all easy to use. Visit http://www.dovepress.com/testimonials.php to read real quotes from published authors. 